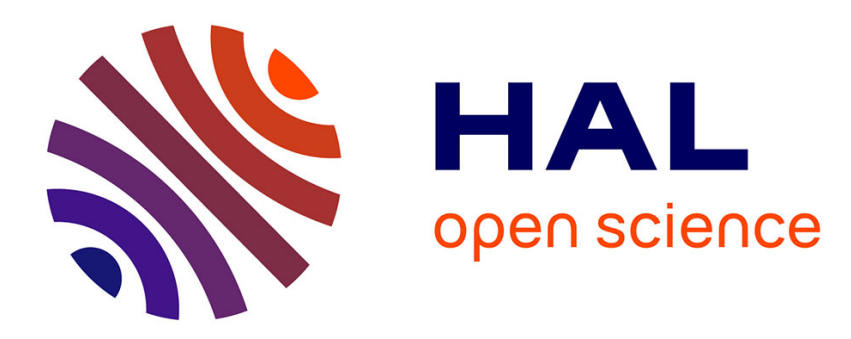

\title{
Asymmetrical loading of a penny-shaped crack in an infinite transversely isotropic medium
}

\author{
M. Dahan
}

\section{To cite this version:}

M. Dahan. Asymmetrical loading of a penny-shaped crack in an infinite transversely isotropic medium. Journal de Physique Lettres, 1980, 41 (21), pp.495-497. 10.1051/jphyslet:019800041021049500 . jpa00231830

\section{HAL Id: jpa-00231830 https://hal.science/jpa-00231830}

Submitted on 1 Jan 1980

HAL is a multi-disciplinary open access archive for the deposit and dissemination of scientific research documents, whether they are published or not. The documents may come from teaching and research institutions in France or abroad, or from public or private research centers.
L'archive ouverte pluridisciplinaire HAL, est destinée au dépôt et à la diffusion de documents scientifiques de niveau recherche, publiés ou non, émanant des établissements d'enseignement et de recherche français ou étrangers, des laboratoires publics ou privés. 


\title{
LE JOURNAL DE PHYSIQUE-LETTRES
}

\section{Asymmetrical loading of a penny-shaped crack in an infinite transversely isotropic medium $\left({ }^{*}\right)$}

\author{
M. Dahan \\ Laboratoire de Mécanique des Solides, Ecole Polytechnique (**), 91128 Palaiseau, France \\ (Reçu le 15 juillet 1980, accepté le 12 septembre 1980)
}

\begin{abstract}
Résumé. - La distribution des contraintes et des déplacements dans un massif infini transversalement isotrope, contenant une fissure plane circulaire, est déterminée quand des forces intérieures, concentrées sur une surface, sont appliquées d'un seul côté de la fissure, à une distance finie.
\end{abstract}

\begin{abstract}
The problem of stress and displacement fields in an infinite transversely isotropic medium is solved when a penny-shaped crack is opened by an asymmetrical system of body forces; the body forces are concentrated on one interior surface situated at a finite distance from the.crack.
\end{abstract}

1. Introduction. - The problem of stress and displacement fields in an infinite medium in the presence of a symmetrical system of body forces has been solved by Sneddon and Tweed [1] for an isotropic material and by Dahan [2] for a transversely isotropic material. The problem of crack opening by an asymmetrical system of body forces, acting on one side of the crack, has been considered by Collins [3] in the isotropic case. The purpose of this paper is to give the complete solution of this problem when the medium is characterized by transverse isotropy, having the $z$-axis as the elastic symmetric axis. We shall assume that the loading is concentrated on a plane internal disc, around the $z$-axis, situated at a finite distance $h$ from the crack.

By using the cylindrical coordinates $(r, \theta, z)$, we shall note $\left(u_{r}, 0, u_{z}\right)$ the components of the displacement field $\left(\sigma_{r r}, \sigma_{\theta \theta}, \sigma_{z z}, \sigma_{r z}\right)$ the non-zero components of the stress tensor. The penny-shaped crack is defined by its radius $r_{0}$ and it is situated in the plane $z=0$ (cf. Fig. 1). If $p(r)$ is the loading on the plane $z=h$, the presence of body forces implies the continuity of displacements $u_{r}, u_{z}$ and shear stress $\sigma_{r z}$ and the discontinuity of normal stress $\sigma_{z z}$ following the condition :

$$
\lim _{\varepsilon \rightarrow 0^{+}}\left[\sigma_{z z}(r, h-\varepsilon)-\sigma_{z z}(r, h+\varepsilon)\right]=p(r),
$$

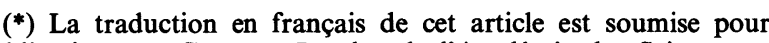
publication aux Comptes Rendus de l'Académie des Sciences.

$(* *)$ L.A. C.N.R.S. no 317 where $p$ is an arbitrary function so defined for $r \geqslant 0$ that the Hankel transform of order zero $p^{\mathrm{H}}$ exists.

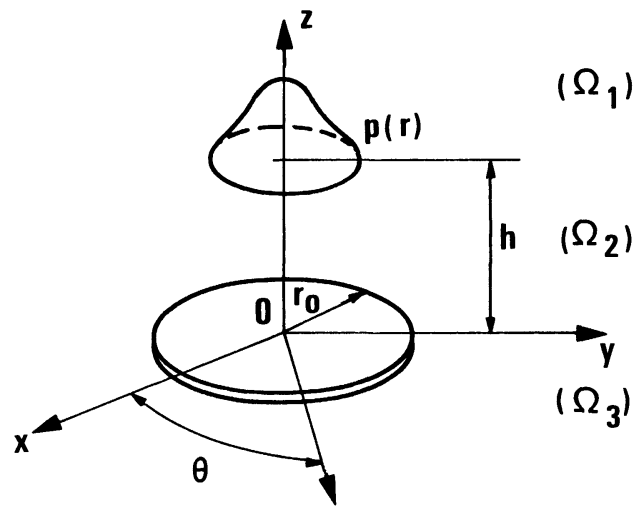

Fig. 1. - Diagram of the problem.

Over the plane $z=0$, the stresses and displacements are continuous in the exterior of the crack $\left(r>r_{0}\right)$; the boundary of which is stress-free, i.e. the stresses $\sigma_{z z}$ and $\sigma_{r z}$ take prescribed values over the surface of the crack, so that :

$$
\begin{aligned}
& \sigma_{z z}(r, 0)=0, \quad 0 \leqslant r<r_{0} . \\
& \sigma_{r z}(r, 0)=0,
\end{aligned}
$$

The remaining boundary conditions assume that 
the components of stress and of displacement vanish as $\left(r^{2}+z^{2}\right)^{1 / 2} \rightarrow \infty$.

2. Resolution. - In order to solve this problem, we have to divide the space in three parts $\Omega_{i}$ :

$$
\begin{aligned}
& \Omega_{1}=\left\{(r, z): r \in \mathcal{R}_{+}, h<z<+\infty\right\}, \\
& \Omega_{2}=\left\{(r, z): r \in \mathcal{R}_{+}, 0<z<h\right\}, \\
& \Omega_{3}=\left\{(r, z): r \in \mathcal{R}_{+},-\infty<z<0\right\} .
\end{aligned}
$$

Using the results given in a previous paper [4] and the notations of a precedent Letter [2], we know that there exists a potential function of the Love type $\varphi$, defined by the components of stress tensor, such that in each part $\Omega_{i}$, we have :

$$
\begin{gathered}
\varphi(r, z)=\int_{0}^{\infty}\left[A_{i}(m) \mathrm{e}^{+s_{1} m z}+B_{i}(m) \mathrm{e}^{+s_{2} m z}+C_{i}(m) \mathrm{e}^{-s_{1} m z}+D_{i}(m) \mathrm{e}^{-s_{2} m z}\right] J_{0}(m r) m \mathrm{~d} m, \\
(r, z) \in \Omega_{i} \quad i=1,2,3 .
\end{gathered}
$$

If we take into account the boundary conditions on the plane $z=h$, the condition at infinity and the continuity of the stresses $\sigma_{z z}$ and $\sigma_{r z}$ over the plane $z=0$, we have the following relations between the twelve functions $A_{i}, B_{i}, C_{i}, D_{i}$ :

$$
\begin{aligned}
& A_{1}(m)=B_{1}(m)=C_{3}(m)=D_{3}(m)=0, \\
& A_{2}(m)=\mathrm{e}^{-m s_{1} h} p^{\mathrm{H}}(m) /\left[2 m^{3} \mathrm{~d} s_{1}\left(s_{1}^{2}-s_{2}^{2}\right)\right], \\
& B_{2}(m)=\mathrm{e}^{-m s_{2} h} p^{\mathrm{H}}(m) /\left[2 m^{3} \mathrm{~d} s_{2}\left(s_{2}^{2}-s_{1}^{2}\right)\right], \\
& C_{1}(m)=\mathrm{e}^{+m s_{1} h} p^{\mathrm{H}}(m) /\left[2 m^{3} \mathrm{~d} s_{1}\left(s_{1}^{2}-s_{2}^{2}\right)\right]+C_{2}(m), \\
& D_{1}(m)=\mathrm{e}^{+m s_{2} h} p^{\mathrm{H}}(m) /\left[2 m^{3} \mathrm{~d} s_{2}\left(s_{2}^{2}-s_{1}^{2}\right)\right]+D_{2}(m), \\
& A_{3}(m)=A_{2}(m)+\frac{s_{1}+s_{2}}{s_{1}-s_{2}} C_{2}(m)+\frac{2 s_{1}}{s_{1}-s_{2}} \cdot \frac{p_{2}}{p_{1}} D_{2}(m), \\
& B_{3}(m)=B_{2}(m)+\frac{s_{2}+s_{1}}{s_{2}-s_{1}} D_{2}(m)+\frac{2 s_{2}}{s_{2}-s_{1}} \cdot \frac{p_{1}}{p_{2}} C_{2}(m) .
\end{aligned}
$$

We have to determine the functions $C_{2}$ and $D_{2}$. For this, by using the equations (2) and the continuity of the displacements in the exterior of the crack for $z=0$, we obtain a system of four integral equations :

$$
\begin{aligned}
& \int_{0}^{\infty}\left[s_{1} g_{1} C_{2}(m)+s_{2} g_{2} D_{2}(m)-\left(g_{1} \mathrm{e}^{-m s_{1} h}-g_{2} \mathrm{e}^{-m s_{2} h}\right) \frac{p^{\mathrm{H}}(m)}{2 m^{3} d\left(s_{1}^{2}-s_{2}^{2}\right)}\right] m^{4} J_{0}(m r) \mathrm{d} m=0,0<r<r_{0}, \\
& \int_{0}^{\infty}\left[s_{2} p_{1} C_{2}(m)+s_{1} p_{2} D_{2}(m)\right] m^{3} J_{0}(m r) \mathrm{d} m=0, r_{0} \leqslant r<\infty, \\
& \int_{0}^{\infty}\left[p_{1} C_{2}(m)+p_{2} D_{2}(m)+\left(p_{1} s_{2} \mathrm{e}^{-m s_{1} h}-p_{2} s_{1} \mathrm{e}^{-m s_{2} h}\right) \frac{p^{\mathrm{H}}(m)}{2 m^{3} \sqrt{d}\left(s_{1}^{2}-s_{2}^{2}\right)}\right] m^{4} J_{1}(m r) \mathrm{d} m=0,0<r<r_{0}, \\
& \int_{0}^{\infty}\left[p_{1} C_{2}(m)+p_{2} D_{2}(m)\right] m^{3} J_{1}(m r) \mathrm{d} m=0, r_{0} \leqslant r<\infty .
\end{aligned}
$$

This system can be solved if we notice the last two equations are two dual integral equations of the unknown function $p_{1} C_{2}+p_{2} D_{2}$. Having determined this function, then the first two equations are dual integral equations of the function $C_{2}$ or $D_{2}$. Thus, the solution of the system (6) is given by :

$$
\begin{aligned}
& C_{2}(m)=\left[s_{1} I(m)-s_{1} J(m)-K(m)\right] / m^{3} p_{1}\left(s_{1}^{2}-s_{2}^{2}\right), \\
& D_{2}(m)=\left[s_{2} I(m)-s_{2} J(m)-K(m)\right] / m^{3} p_{2}\left(s_{2}^{2}-s_{1}^{2}\right),
\end{aligned}
$$

where the functions $I, J, K$ depend on the loading and the geometrical parameters such that :

$$
\begin{aligned}
& I(m)=\frac{1}{\pi \sqrt{d}\left(s_{1}-s_{2}\right)} \cdot \frac{\sin \left(m r_{0}\right)}{m r_{0}} \int_{0}^{\infty}\left(s_{2} p_{1} \mathrm{e}^{-\alpha s_{1} h}-s_{1} p_{2} \mathrm{e}^{-\alpha s_{2} h}\right) p^{\mathrm{H}}(\alpha) \sin \left(\alpha r_{0}\right) \frac{\mathrm{d} \alpha}{\alpha}, \\
& J(m)=\frac{1}{\pi \sqrt{d}\left(s_{1}-s_{2}\right)} \int_{0}^{r_{0}}\left[\int_{0}^{\infty}\left(s_{2} p_{1} \mathrm{e}^{-\alpha s_{1} h}-s_{1} p_{2} \mathrm{e}^{-\alpha s_{2} h}\right) p^{\mathrm{H}}(\alpha) \cos (\alpha t) \mathrm{d} \alpha\right] \cos (m t) \mathrm{d} t,
\end{aligned}
$$




$$
K(m)=\frac{1}{\pi d^{3 / 2}\left(s_{1}-s_{2}\right)} \int_{0}^{r_{0}}\left[\int_{0}^{\infty}\left(g_{1} \mathrm{e}^{-\alpha s_{1} h}-g_{2} \mathrm{e}^{-\alpha s_{2} h}\right) p^{\mathrm{H}}(\alpha) \sin (\alpha t) \mathrm{d} \alpha\right] \sin (m t) \mathrm{d} t .
$$

3. Stress intensity factors. - For further discussions interesting the Fracture Mechanics, we can calculate the different stress intensity factors defined by the limits :

$$
\begin{aligned}
& k_{1}=\lim _{r \rightarrow r^{\ddagger}}\left[2 \pi\left(r-r_{0}\right)\right]^{1 / 2} \sigma_{z z}(r, 0), \\
& k_{2}=\lim _{r \rightarrow r^{\ddagger}}\left[2 \pi\left(r-r_{0}\right)\right]^{1 / 2} \sigma_{r z}(r, 0), \\
& k_{3}=\lim _{r \rightarrow r^{\ddagger}}\left[2 \pi\left(r-r_{0}\right)\right]^{1 / 2} \sigma_{\theta z}(r, 0)=0 .
\end{aligned}
$$

From these definitions and relations (5) and (7), we deduce :

$$
\begin{aligned}
& k_{1}=\frac{-1}{\sqrt{\pi r_{0}} d\left(s_{1}^{2}-s_{2}^{2}\right)} \int_{0}^{\infty}\left(g_{1} \mathrm{e}^{-m s_{1} h}-g_{2} \mathrm{e}^{-m s_{2} h}\right) p^{\mathrm{H}}(m) \sin \left(m r_{0}\right) \mathrm{d} m, \\
& k_{2}=\frac{1}{\sqrt{\pi r_{0} d}\left(s_{1}^{2}-s_{2}^{2}\right)} \int_{0}^{\infty}\left(s_{2} p_{1} \mathrm{e}^{-m s_{1} h}-s_{1} p_{2} \mathrm{e}^{-m s_{2} h}\right)\left[\frac{\sin \left(m r_{0}\right)}{m r_{0}}-\cos \left(m r_{0}\right)\right] p^{\mathrm{H}}(m) \mathrm{d} m .
\end{aligned}
$$

Closed form solutions can be obtained for usual loadings of the cracked solid (uniform loads over a disc, point concentrated force...). For a point force $\left(p^{\mathrm{H}}=P / 2 \pi\right)$, the expressions obtained through a limit operation agree with the results of the only existing isotropic solution given by Kassir and Sih [5].

Moreover, this solution makes possible to calculate the stress intensity factors in the case of two loads $p_{1}$ and $p_{2}$ applied on each side of the crack at distances $h_{1}$ and $h_{2}$. From the principle of superposition, we have the new factors by using for each $k_{i}$ the expressions (10) :

$$
\begin{aligned}
& k_{1}=k_{1}\left(p_{1}, h_{1}\right)+k_{1}\left(p_{2}, h_{2}\right), \\
& k_{2}=k_{2}\left(p_{1}, h_{1}\right)-k_{2}\left(p_{2}, h_{2}\right) .
\end{aligned}
$$

For equal and symmetrically spaced loads, we remark that the factor $k_{1}$ is double the value given by (10) and the factor $k_{2}$ is zero. These expressions agree with the results obtained in the Letter mentioned above [2].

\section{References}

[1] Sneddon, I. N., TweEd, J., Int. J. Fract. Mech. 3 (1967) 317.

[2] Dahan, M., J. Physique Lett. 41 (1980) L-213.

[3] Collins, W. D., Proc. R. Soc., London A 266 (1962) 359.

[4] Dahan, M., Predeleanu, M., C. R. Hebd. Séan. Acad. Sci., Paris 289 (1979) 147.

[5] KassiR, M. K., SIH, G. C., Three dimensional crack problems (Noordhoff Int. Publishing, Leyden) 1975. 